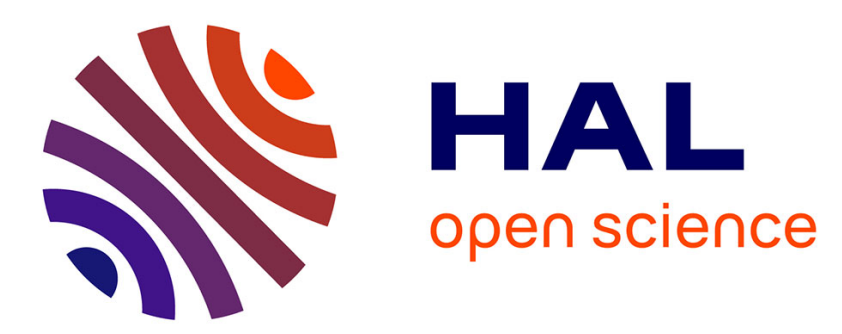

\title{
Positive tree diversity effect on fine root biomass: via density dependence rather than spatial root partitioning
}

Weixian Zeng, Wenhua Xiang, Bo Zhou, Shuai Ouyang, Yelin Zeng, Liang Chen, Gregoire T. Freschet, Oscar Valverde-barrantes, Alexandru Milcu

\section{- To cite this version:}

Weixian Zeng, Wenhua Xiang, Bo Zhou, Shuai Ouyang, Yelin Zeng, et al.. Positive tree diversity effect on fine root biomass: via density dependence rather than spatial root partitioning. Oikos, 2021, 130, pp.1-14. 10.1111/oik.07777 . hal-02987226

\section{HAL Id: hal-02987226 \\ https://hal.science/hal-02987226}

Submitted on 5 Nov 2020

HAL is a multi-disciplinary open access archive for the deposit and dissemination of scientific research documents, whether they are published or not. The documents may come from teaching and research institutions in France or abroad, or from public or private research centers.
L'archive ouverte pluridisciplinaire HAL, est destinée au dépôt et à la diffusion de documents scientifiques de niveau recherche, publiés ou non, émanant des établissements d'enseignement et de recherche français ou étrangers, des laboratoires publics ou privés. 


\title{
Positive tree diversity effect on fine root biomass: via density dependence rather than spatial root partitioning
}

\author{
Weixian Zeng ${ }^{1}$, Wenhua Xiang ${ }^{1,2}$, Bo Zhou ${ }^{1}$, Shuai Ouyang ${ }^{1,2}$, Yelin Zeng ${ }^{1,2}$, Liang \\ Chen $^{1,2}$, Grégoire T. Freschet ${ }^{3}$, Oscar J. Valverde-Barrantes ${ }^{5}$ and Alexandru Milcu, ${ }^{3,4}$
}

${ }^{1}$ Faculty of Life Science and Technology, Central South Univ. of Forestry and Technology, CN-410004 Changsha, Hunan Province, PR China

${ }^{2}$ Huitong National Station for Scientific Observation and Research of Chinese Fir Plantation Ecosystem in Hunan Province, CN-438107 Huitong, PR China

${ }^{3}$ Centre Ecologie Fonctionnelle Evolutive, Univ Montpellier, CNRS, Univ Paul Valéry, EPHE, IRD, Montpellier, France

${ }^{4}$ Ecotron Européen de Montpellier, Univ. Montpellier, CNRS, Montferrier sur Lez, France

${ }^{5}$ Int. Center of Tropical Botany, Florida International Univ., Miami, FL, USA

Corresponding author: Wenhua Xiang, Faculty of Life Science and Technology, Central South Univ. of Forestry and Technology, CN-410004 Changsha, Hunan Province, PR China. E-mail: xiangwh2005@163.com

Decision date: $24-\mathrm{Aug}-2020$

This article has been accepted for publication and undergone full peer review but has not been through the copyediting, typesetting, pagination and proofreading process, which may lead to differences between this version and the Version of Record. Please cite this article as doi: [10.1111/oik.07777]. 


\section{Abstract}

The importance of species richness to ecosystem functioning and services is a central tenet of biological conservation. However, most of our theory and mechanistic understanding is based on diversity found aboveground. Our study sought to better understand the relationship between diversity and belowground function by studying root biomass across a plant diversity gradient. We collected soil cores from 91 plots with between 1 to 12 aboveground tree species in three natural secondary forests to measure fine root ( $\leq 2 \mathrm{~mm}$ in diameter) biomass. Molecular methods were used to identify the tree species of fine roots and to estimate fine root biomass for each species. This study tested whether the spatial root partitioning (species differ by belowground territory) and symmetric growth (the capacity to colonize nutrient-rich hotspots) underpin the relationship between aboveground species richness and fine root biomass. All species preferred to grow in nutrient-rich areas and symmetric growth could explain the positive relationship between aboveground species richness and fine root biomass. However, symmetric growth only appeared in the nutrient-rich upper soil layer $(0-10 \mathrm{~cm})$.

Structural equation modelling indicated that aboveground species richness and stand density significantly affected fine root biomass. Specifically, fine root biomass depended on the interaction between aboveground species richness and stand density, with fine root biomass increasing with species richness at lower stand density, but not at higher stand density. Overall, evidence for spatial (i.e. vertical) root partitioning was inconsistent; assumingly any roots growing into deeper unexplored soil layers were not sufficient contributors to the positive diversity-function relationship. Alternatively, density-dependent biotic interactions affecting tree recruitment are an important driver affecting productivity in diverse subtropical forests but the usual root distribution patterns in line with the spatial root partitioning hypothesis are unrealistic in contexts where soil nutrients are heterogeneously distributed.

Keywords: biodiversity-ecosystem function, spatial root partitioning, molecular methods, stand density, symmetric root growth 


\section{Introduction}

There is scientific consensus that biodiversity strongly affects ecosystem functions and services, such as belowground biomass production and nutrient cycling, and the services provided to human (Bardgett and van Der Putten 2014, Gould et al. 2016). However, we lack mechanistic understanding of the ways biodiversity affects functioning, and especially its impact on belowground processes. Fine roots (roots $\leq 2 \mathrm{~mm}$ in diameter) are essential to belowground plant productivity (Bardgett et al. 2014, Mommer et al. 2015), accounting for between $22 \%$ and $76 \%$ of net primary productivity in terrestrial ecosystems (Gower et al. 1996, Jackson et al. 1997, Ma and Chen 2016). Research on the fine root dynamics in natural forests (Gale and Grigal 1987, Hendrick and Pregitzer 1992, Jackson et al. 1997) lags behind our understanding of aboveground diversity-function relationships (Huang et al. 2010, Zhang et al. 2012, Liang et al. 2016) due to logistical difficulties with sampling (Mommer et al. 2010, Zhang et al. 2012, Ma and Chen 2017). Fine roots are responsible for water and nutrient uptake and play an important role in mediating species coexistence, affecting spatial niche partitioning belowground and impacting broader niche space dynamics, ecosystem productivity (de Kroon et al. 2012, Valverde-Barrantes et al. 2015, Mommer et al. 2016) and nutrient cycling (Adams et al. 2013, Freschet and Roumet 2017). Understanding the mechanisms controlling fine root production are essential to disentangle plant interactions, resource use and the resilience of ecosystems to perturbation (Ma and Chen 2016, 2017).

The mechanisms by which biodiversity affects the total standing biomass and production of fine roots is a topic of debate. Most evidence supports the positive relationship between species richness and root production (Brassard et al. 2013, Xiang et al. 2015, Ma and Chen 2017, 2018, Mommer et al. 2018), but non-significant and negative effects have been reported (Jacob et al. 2013, Domisch et al. 2015). Similarly, 
a positive relationship between species richness and fine root biomass was reported in grasslands (Oram et al. 2018, Mahaut et al. 2020), while results from temperate forests (Meinen et al. 2009, Valverde-Barrantes et al. 2015) exhibited contrasting results. The contrasting findings may stem from the scale- dependent relationships between tree species richness and ecosystem function in forests (Chisholm et al. 2013). The causes of variation may include factors like site conditions, species composition and functional diversity, plant density and spatial arrangement, and stand legacy and development stage (Brassard et al. 2013, Chisholm et al. 2013, Forrester and Bauhus 2016). The mechanisms remain unclear for the overall positive effect of diversity on fine root production in ecosystems dominated by woody species, though the effect is widespread according to a recent meta-analysis (Ma and Chen 2016).

Resource partitioning is hypothesized to occur when species use different portions of the available resource pool across space, time and chemical form. Partitioning is expected to result in the more complete use of resources as diversity increases (Tilman 1999; Barry et al. 2020). The hypothesis predicts that higher species richness will also increase productivity by increasing the likelihood of including species with complementary traits and resource acquisition strategies, although some species have life-history traits that allow them to surpass the average biomass in mixed communities in certain circumstances. Consequently, more diverse forest stands have the potential to support more above and belowground biomass. Indeed, root biomass in mixed forests may be greater due to resources partitioning that avoid interspecific competition, at least when the major resource limitation for plant growth is belowground (Mahaut et al. 2020). For instance, the depletion of resources in surface soils due to competition may cause plants to allocate root growth to deeper horizons, resulting in more evenly distributed resource use across the whole profile (Mueller et al. 2013). The positive relationship between species richness and belowground biomass may, therefore, result 
from more fine roots growing deeper into vertical soil volumes in species-rich stands (Brassard et al. 2013). This phenomenon is termed spatial root partitioning, where species alter their colonization of belowground spaces as a result of resource partitioning.

In species rich forests, root biomass may also be impacted by changes in tree root growth strategies (Valverde-Barrantes et al. 2015). Root growth can be symmetric or asymmetric, depending on the response of tree species to nutrient availability according to soil horizon or heterogeneity. In a scenario of symmetric growth, all species have an equal capacity to detect and colonize nutrient-rich hotspots, resulting in a positive correlation between root biomass and species richness in areas with higher nutrient availability. Conversely, in an asymmetric scenario, a limited number of pre-emptive species invest more in root growth or alter morphological traits to increase nutrient absorption efficiency. In this scenario, less competitive species are excluded from or less effective to take advantage from high nutrient patches.

Negative biotic feedbacks can alter plant diversity-productivity relationships, such as density dependence effects like the Janzen-Connell effect (Petermann et al. 2008, Schnitzer et al. 2011). The negative biotic feedbacks occur when enemies and/or pathogens are sufficiently species-specific that tree performance is suppressed when they occur among members of their own species in a negative density-dependent manner, leading to less growth suppression in plant communities with diverse species relative to monocultures (Janzen 1970, Connell 1971, Johnson et al. 2012). Thus, stand density is another important factor influencing the relationship between species richness and root biomass, where richness might be positively correlated with stand density (Kennedy et al. 2002, Marquard et al. 2009). As a result, the assembly of plant communities with diverse species could be favoured compared to monocultures (Barry et al. 2019) and both species richness and stand density need to be considered when understanding effects on fine root biomass (Forrester and Bauhus 2016). 
It is critical to identify the relative biomass and spatial distribution of plant species belowground to test whether the relationship between species richness and fine root biomass is driven by resource partitioning (i.e. spatial distribution) or growth strategy (i.e. symmetric vs. asymmetric). Until recently, the identification of fine roots was a limiting factor in ecological studies since the roots of distinct species closely intermingle and can be difficult to distinguish morphologically (Mommer et al. 2010). Molecular methods provide an effective approach to identify roots in diverse plant communities (Jones et al. 2011, Hiiesalu et al. 2012, Frank et al. 2015, Zeng et al. 2015, 2017), making it possible to estimate standing root biomass at the species level (Valverde-Barrantes et al. 2015, Oram et al. 2018).

Most studies on the mechanisms controlling diversity-function relationships have been conducted by experimental manipulation (He et al. 2005, Schnitzer et al. 2011, Mueller et al. 2013, Domisch et al. 2015, Oram et al. 2018). However, an increasing number of studies have proven that the relationships between biodiversity and ecosystem function occurring in naturally assembled communities might deviate from experimental manipulations (Hooper et al. 2005, Leuschner et al. 2009, Cardinale et al. 2011, van der Plas 2019). Therefore, with the help of new molecular tools, we investigated how the standing fine root biomass varied along a tree diversity gradient in naturally-occurring subtropical forests in southern China. These forests are highly diverse (Bruelheide et al. 2011), productive (Yu et al. 2014) and represent complex successional dynamics (Xiang et al. 2015), making them a relevant model system for studying belowground tree interactions.

In trying to elucidate the complex linkages between root productivity, whole-plant productivity and the spatial resource partitioning underlying species coexistence, it is critical to measure standing fine root biomass (total amount at a certain time) rather than solely fine root productivity (amount per year). The acquisition of belowground 
resources relies largely on maintaining absorptive fine root biomass, which can be done by increasing fine root lifespan and/or increasing productivity (Eissenstat 1992, Hodge 2004). Measures of plant standing biomass capture key aspects of the positive diversity-function relationship (Cardinale et al. 2007, Zhang et al. 2012), as commonly recognized aboveground (Cardinale et al. 2011, Liang et al. 2016, Williams et al. 2017).

Here, we conducted a study to test the underlying mechanisms for the positive correlation between standing fine root biomass and tree species richness (see Figure 1). In our study framework, we address potential confounding factors like the possible increased allocation to belowground biomass under increased belowground competition or nutrient limitation (Gersani et al. 2001, Craine 2006). Firstly, we hypothesized that a proxy for aboveground productivity (leaf area index) would increase with species richness and positively correlate with root biomass. Secondly, we expected that spatial root partitioning would be a primary mechanism underlying the positive relationship between fine root biomass and species richness. To test this hypothesis, we measured whether fine root biomass had filled a greater soil volume and spread more evenly, resulting from allocation to deep soils as tree species richness increased (Figure 1-b). Thirdly, we expected root growth strategy would be associated with high soil resource availability. We examined whether all species had an equal tendency to proliferate in nutrient-rich sites (i.e. symmetric root growth; Figure 1c(i)) versus the dominance of fewer, select species (i.e. asymmetric growth; Figure 1c(ii)). Finally, we tested whether a higher stand density flattened the diversity-function relationship due to a negative density-dependence effect. The interactions between aboveground tree species richness, soil nutrient and stand density on fine root biomass were considered to disentangle the complex relationships driving diversity-function relationships.

\section{Materials and methods}




\section{Study site description}

This study was carried out in the Dashanchong Forest Park $\left(28^{\circ} 23^{\prime} 58^{\prime \prime}-28^{\circ} 24^{\prime} 58^{\prime \prime} \mathrm{N}\right.$, $113^{\circ} 17^{\prime} 46^{\prime \prime}-113^{\circ} 19^{\prime} 08^{\prime \prime}$ E), in Changsha County, Hunan Province, China. The altitude ranged from $55 \mathrm{~m}$ to $217 \mathrm{~m}$ above sea level, with hilly topography. This region has a humid mid-subtropical monsoonal climate with annual mean temperatures of $17.3^{\circ} \mathrm{C}$ and mean monthly temperatures of $-10.3{ }^{\circ} \mathrm{C}$ in the coolest month (January) and $39.8{ }^{\circ} \mathrm{C}$ in the warmest month (July). Mean annual precipitation is $1416 \mathrm{~mm}$, and the minimum and maximum annual precipitation is $936 \mathrm{~mm}$ and $1954 \mathrm{~mm}$ (year period during 1954-2010) (Ouyang et al. 2016, Wu et al. 2019). The soil is a shallow (30 cm deep), well-drained clay loam overlying slate and shale parent rock, classified as Ferralsols (WRB 2006).

In this study, we selected three typical secondary forests: (1) a mixed coniferous and evergreen broad-leaved forest at an early successional stage, dominated by Pinus massoniana and Lithocarpus glaber (PM); (2) a broad-leaved deciduous forest at an intermediate successional stage, dominated by Choerospondias axillaris (CA); and (3) an broad-leaved evergreen forest at late successional stage, dominated by L. glaber and Cyclobalanopsis glauca (CG). The PM and CG were located on two hilly ridges separated by a valley with a distance of $200 \mathrm{~m}$ and these two forests were $1500 \mathrm{~m}$ away from CA.

\section{Sampling design}

In 2013, we identified three 1-ha forest sites corresponding to each forest type (PM, CA and CG). Each site was divided in 100 plots of $10 \times 10 \mathrm{~m}$. The stand characteristics of each plot have previously been reported (Liu et al. 2014, Zhu et al. 2016). A subset of 91 plots, representing a gradient in tree species richness, were chosen: 30 plots for PM (ranging from 2 to 9 tree species); 31 plots for CA (1-12 tree species); and 30 plots for CG 
(1-11 tree species; see overview in Figure S1). Trees within each plot were mapped, identified, and the diameter at breast height ( $\mathrm{DBH}$, at $1.3 \mathrm{~m}$ above the ground), height $(\mathrm{H})$ and basal area $(\mathrm{BA})$ of all trees with $\mathrm{DBH} \geq 4 \mathrm{~cm}$ were measured. The stand density was determined by counting the number of stems within each plot. Pielou's evenness was determined based on DBH according to Pielou (1966). These stand characteristics of each forest types are displayed in Table S1. Species functional classification included: evergreen conifer, broad-leaved deciduous, broad-leaved evergreen and shrub species (lio et al. 2014). The dominant species were: P. massoniana, C. axillaris, L. glaber, $C$. glauca, Liquidambar formosana, Cleyera japonica, Cinnamomum camphora and Loropetalum chinense.

In August 2016, we sampled one soil core $(10 \mathrm{~cm}$ in internal diameter) to $30 \mathrm{~cm}$ depth (i.e. down to bedrock) in the centre of each plot, which we further separated in three soil depths of 0-10 cm, 10-20 cm and 20-30 cm. Fine roots (defined here as roots $\leq 2 \mathrm{~mm}$ in diameter) were collected from soil samples at each depth and placed into separated plastic bags in the field. A total of 273 soil samples were collected and transported to the laboratory stored at $4{ }^{\circ} \mathrm{C}$ for further analysis (within 1 week). Adjacent to the location of each fine root sampling (within $30 \mathrm{~cm}$ distance) we collected an additional soil sample per plot $(\mathrm{n}=91)$ for chemical analysis of nutrient concentrations using the same sampling method. In July 2014, the leaf area index (LAI) was estimated based on hemispherical photographs taken at the centre of each plot with a SY-S01A device (Shiya Scientific and Technical Cooperation, Hebei, China), as previously described (Zhu et al. 2016). We assumed that the LAI values sampled in July 2014 are representative of the actual values at the time of the fine root sampling in August 2016, since numerous studies show that the LAI in tropical forests varies only slightly between years (Le Dantec et al. 2000, Barr et al. 2004, Cristiano et al. 2014). 


\section{Root biomass and species identification}

In the laboratory, fine root mass was separated from soil by sieving and any adhering soil aggregates were removed manually. The remaining soil was placed in a bucket filled with tap water and then gently washed over sieves $(0.2 \mathrm{~mm}$ mesh) to collect all remaining fine root fragments. Roots were divided between live and dead pools, based on morphological criteria. Live roots were intact, tough and flexible, whereas dead roots had a dark cortex, were rigid and broke easily (Brassard et al. 2013). All dead roots were discarded. For each sample, fine roots were then randomly divided into two parts. In the first part, 30 pieces of intact fine roots (about $5 \mathrm{~cm}$ length) were randomly selected, weighed for fresh weight $\left(\mathrm{W}_{\text {fresh-first-part }}\right)$ and then stored at $-80^{\circ} \mathrm{C}$ for DNA-based species identification. If the total number of intact fine roots was less than 60 pieces, a random selection of half the number of intact fine roots was made. The second part was used to determine the total fine root biomass $\left(\mathrm{W}_{\text {total }}\right)$ according to following formula:

$$
\mathrm{W}_{\text {total }}=\left(\mathrm{W}_{\text {fresh-first-part }}+\mathrm{W}_{\text {fresh-second-part }}\right) * \mathrm{~W}_{\text {dry-second-part }} / \mathrm{W}_{\text {fresh-second-part }}
$$

where $\mathrm{W}_{\text {fresh-second-part }}$ corresponds to the fresh weight, and $\mathrm{W}_{\text {dry-second-part }}$ corresponds to weight following oven-drying at $65^{\circ} \mathrm{C}$, after a constant weight was achieved.

We chose to run our analyses on 30 pieces of intact fine roots, since a prior study (Jones et al. 2011) found calculations based on the identifications on 10 fine root fragments per sample produced an underestimation of actual richness. At the depth of 0-10 cm of one plot in PM (aboveground 9 richness), one plot in CA (aboveground 12 richness) and one plot in CG (aboveground 11 richness) representing the most diverse plots, we also tested whether adding an additional 20 intact root fragments (i.e. using a total of 50 pieces of intact fine roots) improved the detection of species. In total, 273 samples of 30 root fragments, plus the three additional samples of 20 root fragments, were used for estimating species richness by DNA sequencing. DNA extractions were performed by grinding each root sample in liquid nitrogen for $1 \mathrm{~min}$, and using the Plant 
DNA Kit, as per the recommended use (Tiangen Biotech Co. Ltd., Beijing). DNA purity was measured by the ratio of absorbance at $260 \mathrm{~nm} / 280 \mathrm{~nm}$, which ranged from 1.75 to 1.85 and was considered high quality DNA.

Tree species were identified using polymerase chain reaction amplification of the $r b c$ La sequence, using the primers 5'-ATGTCACCACAAACAGAGACTAAAGC-3' and 5'-GT AAAATCAAGTCCACCRCG-3', following a method described by Kress et al. (2009), which was able to distinguish fine roots of tree species. PCR was performed using an Eppendorf Mastercycler with a total reaction volume of $20 \mu$, containing $8 \mu \mathrm{l}$ Quick Taq $^{\mathrm{TM}}$ DyeMix (TOYOBO Ltd.), $1 \mu \mathrm{l}(10 \mu \mathrm{M})$ for each of the primers and $1.5 \mu \mathrm{l}$ of template DNA. Amplification was performed with the following conditions: 5 min denaturation at $94{ }^{\circ} \mathrm{C}$ and 29 cycles of 30 s denaturation at $94{ }^{\circ} \mathrm{C}, 30 \mathrm{~s}$ annealing at 52 ${ }^{\circ} \mathrm{C}, 45$ s extension at $72{ }^{\circ} \mathrm{C}$, followed by a final extension at $72{ }^{\circ} \mathrm{C}$ for $5 \mathrm{~min}$. PCR products were purified using a $1.0 \%$ agarose gel in $0.5 \times$ TAE by electrophoresis. PCR product sequencing was performed by BioSune biotechnology (Shanghai Co., Ltd.) and $r b c$ La sequences were aligned using a BLAST search from our previous established $r b c$ La library (unpublished data) with GENEDOC software. This method successfully identified coniferous, broad-leaved deciduous, broad-leaved evergreen and shrub species, but no herbs, grasses or other understory vegetation species (Table S2).

\section{Soil chemical analyses}

Large debris was removed from each soil sample used in chemical analyses in the field, before transporting the soil core at $4{ }^{\circ} \mathrm{C}$ to the laboratory. For each sample, $500 \mathrm{~g}$ of fresh soil was air-dried and sieved to $2 \mathrm{~mm}$ prior to chemical analyses. Soil organic carbon $(\mathrm{C})$, total nitrogen $(\mathrm{N})$ and total phosphorus $(\mathrm{P})$ were determined following Jiang et al. (2017). 
$\mathrm{C}$ was measured by the $\mathrm{K}_{2} \mathrm{Cr}_{2} \mathrm{O}_{7} / \mathrm{H}_{2} \mathrm{SO}_{4}$ oxidation method. Total $\mathrm{N}$ was determined with the Semimicro-Kjeldahl method by using Kjeltec K9840 automatic azotometer. Total $\mathrm{P}$ was measured with the sodium hydroxide $(\mathrm{NaOH})$ fusion and the $\mathrm{Mo-Sb}$ colorimetric method by using spectrophotometry (Institute of Soil Science 1978). All measurements were performed in triplicate. Additional measurements were carried out for samples exhibiting high levels of variation among triplicates. The measurements were averaged to minimize measurement errors. The standard error and deviation associated with each average were estimated.

\section{Data analysis}

The proportion of fine root biomass for each species was calculated as the proportion of biomass assigned to roots fragments identified by DNA sequencing (Jones et al. 2011). Given the random sampling of 30 roots per sample at each depth, one sequence was assumed to represent one-thirtieth of the total fine root biomass. To assess the fine root partitioning between layers and within a layer, we calculated the inverse of the coefficient of variation (inverse $\mathrm{CV}$ ) based on the biomass of each species per depth, using the equation:

inverse $\mathrm{CV}=\mu_{\text {biomass }} / \mathrm{SD}_{\text {biomass }}$

where $\mu_{\text {biomass }}$ corresponds to the mean biomass across depth or within depth, and $\mathrm{SD}_{\text {biomass }}$ corresponds to the biomass standard deviation across depth or within depth.

The inverse CV across depth is an indicator to reflect spatial root partitioning (Barry et al. 2020) and we preferred the inverse CV because its interpretation is more intuitive (Tilman 1999). A high inverse CV across depth corresponds with a more even distribution of fine root biomass across soil depths, with more root mass allocated to deeper layers. When across-depth inverse CV is low, the fine root biomass is mostly concentrated at surface layer soils. We used the within-depth inverse CV to quantify 
variability in fine root biomass among different species at a given soil layer, which reflect the root growth strategies. A higher within-depth inverse CV indicates symmetric root growth, due to low variation in fine root biomass of diverse species in that layer. Contrastingly, the dominance of few species would be reflected in a low within-depth inverse $\mathrm{CV}$, indicating an asymmetric growth strategy. Mean rooting depth was calculated as the sum of roots in each soil layer multiplied by the mean depth of layer and then divided by the total of roots in all layers (Mommer et al. 2010).

The statistical software R 3.2.0 (R Development Core Team 2015) was used to perform all data analysis and to produce figures. To best capture the shape of the relationship between tree species richness and fine root biomass, we tested linear $(y=a$ $+\mathrm{bx})$ as well as several saturating functions [2-parameter, 3-parameter $(\mathrm{y}=\mathrm{a}-\mathrm{be}-\mathrm{cx})$ and Michaelis-Menten exponential functions]. The best fit was assessed based on Akaike Information Criterion (AIC). As the data were best described by a linear fit, a generalized linear model was used to assess the effect of tree species and forest types simultaneously on total root biomass and inverse $\mathrm{CV}$ across layers $(\mathrm{R}$ syntax: "model $=$ glm (response variable $\sim$ richness + forest_type"). We further analysed relationships between factors and aboveground tree species richness with a linear mixed effects approach using the "nlme" package version 3.1-137 (Pinheiro et al. 2017) following previously described guidelines (Zuur et al. 2009). For the response variables tested at the layer level (root biomass in each depths and inverse CV within depths), the random effect of the model was the depth within each plot, nested to account for pseudoreplication. The following R syntax was used: 'model = lme (response variable $~$ richness + forest_type, random $=\sim 1 \mid$ plot, weights $=$ varIdent $($ form $=\sim 1 \mid$ layer $))^{\prime}$. The 'varIdent' weighting function was used to correct for heteroscedasticity (Zuur et al. 2009) resulting from differing levels of variation among the soil layers. The relationships between root-related parameters, stand structure factors and soil nutrient 
content were tested with a similar approach, with each implemented as fixed predictors in the model. Stand density was standardized by weighting the total BA in each plot with the "weights" package (Pasek et al. 2020), since the size of different stands was different.

Structural equation modelling (SEM) was used to examine the effects of species richness, soil nutrients $(\mathrm{C}, \mathrm{N}$ and $\mathrm{P})$, stand density and forest types on fine root biomass in each soil layer with the "lavaan" package (Rosseel 2012). To account for potential selection effects (Aarssen 1997), we tested the role of the presence/absence of several tree species that were frequently present in the plots by introducing these species as covariates in the model. The "interact_plot" function from the package "jtools" version 1.1.1 (Long 2018) was used for plotting two-way interactions with continuous variables. Marginal $\left(\mathrm{mr}^{2}\right)$ and conditional $\left(\mathrm{cr}^{2}\right) \mathrm{r}^{2}$-values representing the variance explained by the fixed and fixed + random effects, respectively, were obtained with the "r.squaredGLMM" function from the MuMIn R package (Nakagawa and Schielzeth 2013).

\section{Results}

\section{Molecular analysis of species proportions}

We successfully amplified $r b c$ La sequences in all samples and identified a total of 32 different species of root fragments (Table S2). The upper 0-10 cm layer had the highest belowground species richness (up to 9 species), with a mean of $4.2( \pm 1.5 \mathrm{SD})$ species. The lowest belowground species richness occurred at a depth of 20-30 cm (between 1-6 species), with a mean of 2.8 ( $\pm 1.1 \mathrm{SD})$ species. When a higher number of roots was sequenced (+ additional 20 pieces of intact fine roots), the estimated belowground species richness did not change and the average relative proportions of each species only varied within $2 \%$ between total tested 30 and 50 of pieces of intact fine roots sample. This 
demonstrated that a sampling of 30 fragments of fine root in each depth of a plot provided an acceptable estimate of richness and proportions of each species. As expected, belowground species richness correlated positively with aboveground species richness for all three forest types (Figure 2), with $\mathrm{r}^{2}$ values ranging from 0.48 to 0.86 . This relationship was driven, in part, by the absence of species and not necessarily due to a failure to detect species.

\section{Relationships between species richness, fine root biomass and leaf area index}

The total standing fine root biomass (the sum of $0-30 \mathrm{~cm}$ depth) was positively correlated with aboveground species richness. On average, we found an increase of $8.55 \mathrm{~g}$ root biomass for each additional aboveground tree species presented in the plots $(p=0.003)$ (Figure 3a, Table S3). LAI, i.e. the investment in aboveground light acquisition, was significantly positively correlated to aboveground species richness ( $p=0.050$ ) (Figure $3 b)$ and fine root biomass $(p=0.012)$ (Figure 3c). There were no significant effects of forest type on fine root biomass $(p=0.120)$ and LAI $(p=0.400)$.

Of the total fine root biomass, $57.5 \%$ was found in the upper $0-10 \mathrm{~cm}$ layer, with $25.0 \%$ at $10-20 \mathrm{~cm}$ and $17.5 \%$ at $20-30 \mathrm{~cm}$ layer. Species richness did not correlate with mean rooting depth $(p=0.290)$ (Figure S2). There were significantly interactive effects between aboveground species richness $\times$ depth on the fine root biomass $(p=0.003)$

(Table 1). Specifically, fine root biomass strongly increased with aboveground species richness in the upper $(0-10 \mathrm{~cm})$ layer (Figure $3 \mathrm{~d}$, Table 1), with a small increase in the intermediate layer $(10-20 \mathrm{~cm})$ and no increase in the lower $(20-30 \mathrm{~cm})$ layer.

\section{Evenness of root distribution}

The across-depth inverse CV, our measure of spatial partitioning, was not significantly correlated with aboveground species richness (Figure 4a, Table 1). However, the within-depth inverse CV was significantly correlated by the interaction of aboveground 
species richness $\times$ depth (Table 1). This interaction resulted from the decreased evenness of root biomass in deeper layers $(10-20 \mathrm{~cm}$ and $20-30 \mathrm{~cm})$ where less nutrients are available (see section below), but not in the more nutrient-rich upper layer $(0-10 \mathrm{~cm})$ (Figure 4b).

\section{Relationship with soil nutrients}

Overall, soil C, N and P significantly varied with depth in a decreasing gradient from the upper to lower depths (Figure S3). The soil C and N contents of the upper layer $(0-10 \mathrm{~cm})$ were significantly higher than those of the deeper soil layers $(10-20 \mathrm{~cm}$ and $20-30 \mathrm{~cm})$ (Figure S3), so we defined the upper layer $(0-10 \mathrm{~cm})$ as the nutrient-rich layer, and the deeper layers $(10-20 \mathrm{~cm}$ and $20-30 \mathrm{~cm})$ as the nutrient-poor layer. No significant effect of aboveground species richness on soil nutrients was found. The within-depth inverse CV of fine root biomass in the upper nutrient-rich soil was significantly correlated by the interaction between aboveground species richness and soil $\mathrm{C}$ and $\mathrm{N}$, but not $\mathrm{P}$ (Table 2). For all three models, the fitted coefficient for the aboveground species richness $\times$ nutrient interaction was positive, indicating higher predicted values of within-depth inverse CV with increasing soil nutrient content, implying higher evenness of root biomass contribution of the different species with increasing soil nutrient pools in the upper (0-10 $\mathrm{cm}$ ) layer (Figure 5). Moreover, an additional model run with all three nutrients simultaneously, found a significant $\mathrm{C} \times \mathrm{N} \times \mathrm{P}$ interaction $\left(\mathrm{F}_{1,165}=4.48, p=0.03\right)$. This interaction could not be further simplified by maximum likelihood tests, and the fitted coefficient was positive, indicating the evenness of the root biomass within the upper layer $(0-10 \mathrm{~cm})$ increased with the soil nutrients (Table S4). In contrast, no significant interactive effect was observed within the deeper nutrient-poor soil layers $(10-20 \mathrm{~cm}$ and 20-30 cm). 


\section{Testing for density and species sampling effects}

Only stand density had a significant relationship with fine root biomass (Table S5) in testing factors related to stand structure (e.g. average $\mathrm{DBH}$, average $\mathrm{H}$, average $\mathrm{BA}$, stand density and Pielou's evenness). The SEM model revealed a significant positive bidirectional relationship between aboveground species richness, fine root biomass, and stand density at the $0-10 \mathrm{~cm}$ depth, explaining $10 \%$ variation of fine root biomass (Figure 6). Soil nutrients and forest types had non-significant effects on root biomass (Figure 6). In subsoil layers $(10-20 \mathrm{~cm}$ and $20-30 \mathrm{~cm})$, no significant effects of tree species, stand density, soil nutrients and forest types on fine root biomass were detected by using the SEM method.

To better understand the drivers behind the diversity-root biomass relationship, and account for sampling effects due to the presence/absence of species, we incorporated stand density and species identity, alongside aboveground species richness, into the model as predictors of fine root biomass. According to AIC, the minimal adequate model retained to predicting the presence of $C$. glauca included a significant density $\times$ aboveground species richness interaction $\left(\mathrm{F}_{1,82}=4.21, p=0.038\right)$. The presence of $C$. glauca, had a major impact on root biomass, increasing it, on average, by $40.41 \mathrm{~g}$. These results indicate that the tree species richness effect on root biomass varied with stand density (Figure 7; Table S6). The interaction indicates lower fine root biomass at low tree diversity levels and low density, but not at high density levels (Figure 7c).

\section{Discussion}

\section{Molecular methods are sufficiently accurate to estimate species-specific fine root}

\section{biomass}

The resource partitioning is often put forward as one of the main mechanisms of enhancing ecosystem functioning; however, the evidence of resource partitioning by 
roots belowground is weak and often conflicting (Brassard et al. 2013,

Valverde-Barrantes et al. 2015, Xiang et al. 2015, Ma and Chen 2016, 2017). At least in part, this could be related to the methodological challenges associated with quantifying the root biomass as the diversity of tree species increases. Our findings indicate that DNA sequencing-based methods are a reliable approach of estimating fine root biomass in species-rich mixtures, consistent with previous studies. To date, there are three popular molecular methods for analysing the fine root samples: the next-generation sequencing method, the quantitative real time-PCR (qPCR) method and the universal markers method (Mommer et al. 2011). Next-generation sequencing is an effective method to identify the species, but is far more expensive than the other methods (Grada and Weinbrecht 2013). Currently, qPCR is the most popular method in grasslands, where no more than eight species co-exist (Mommer et al. 2010, Hendriks et al. 2015, Oram et al. 2018), and is constrained by the difficulty of developing species-specific primers where a large number of species co-exist (Zeng et al. 2017). Thus, in this study we chose the universal markers method, which has been proven that it could accurately identify a large number of tree species in forests (Jones et al. 2011, Kesanakurti et al. 2011).

Our results show a good agreement between above- and belowground tree species richness using the universal markers method (Figure 2) and suggest that our sampling strategy and methodology are appropriate for detecting species based on fine root fragments. In several instances, a greater number of species were detected belowground than aboveground, consistent with previous reports (Pärtel et al. 2012). This is likely due to the wide lateral spread of roots, with belowground species occasionally corresponding to trees from outside the plots (Kesanakurti et al. 2011, Zeng et al. 2017). Furthermore, we likely underestimated aboveground species richness by only including trees with a $\mathrm{DBH} \geq 4 \mathrm{~cm}$. In addition, some aboveground tree species were not detected in our DNA-based survey of fine roots, which may have resulted from the fine roots of some 
plants failing to reach the coring sites in the middle of the plot, or in too low an abundance to be detected.

\section{Fine root biomass is influenced by soil nutrient distribution}

The positive correlation between tree species richness and fine root biomass (Figure 3a) was consistent with previous studies on fine root biomass (Liu et al. 2014, Frank et al. 2015, Milcu et al. 2016). Our results suggest this pattern might be attributed to an increase in belowground competition for nutrients with increasing tree diversity (Gersani et al. 2001, Craine 2006). The increased LAI associated with aboveground tree species richness also contributes to fine root biomass, as it leads to higher net primary productivity (NPP) and more carbon allocated belowground for root growth and nutrient uptake. The positive relationship between LAI, root biomass and aboveground species richness indicates that increasing tree species richness stimulated both fine root biomass and aboveground leaf development (Mahaut et al. 2020), in support of our first hypothesis.

We found little evidence in support of our hypothesis that spatial root partitioning would contribute to the positive diversity-function relationship. The higher biomass in the top layer $(0-10 \mathrm{~cm})$ was correlated with increasing tree species richness and this correlation disappeared in subsoil layers $(10-20 \mathrm{~cm}$ and $20-30 \mathrm{~cm})$. This result indicates that more belowground biomass allocation with increasing tree species richness was not associated with a greater deep volume of soil infiltrated by fine roots (Figure 3d; Figure 4a). This is in line with the findings of several grassland studies that found that plant roots tended to aggregate in the dense topsoil layer despite increasing diversity (von Felten and Schmid 2008, Mommer et al. 2010). Despite competition, plants may not invest in deeper roots due to the observed decrease in nutrients with depth. Instead, plants appear to compete more efficiently for nutrients, with most species allocating new growth in the top 
soil where the nutrient availability is higher. Concentrations of soil $\mathrm{C}, \mathrm{N}$ and $\mathrm{P}$ were highest in the uppermost layer of the soil (Figure S3) where we observed the greatest investment in fine root biomass (Caldwell et al. 1996). The high values of within-depth inverse $\mathrm{CV}$ in the nutrient-rich top layer (Figure $4 \mathrm{~b}$ ) indicates the nutrient hotspots were most evenly explored. Higher richness did not lead to vertical avoidance, but increased foraging for the nutrient-rich topsoil layer. Furthermore, the within-depth inverse CV of the upper nutrient-rich soil layer was strongly affected by the interaction between aboveground species richness and soil $\mathrm{C}$ (or N) (Figure 5), a result that is in accordance with the symmetric growth hypothesis. Overall, these findings are in agreement with a previous study (Valverde-Barrantes et al. 2015) which found that roots of all tree species tended to grow in nutrient-rich areas and higher fine root biomass was associated with an aggregation of species. However, we acknowledge that we cannot completely discount the possibility that plant resource uptake by deeper roots, though lower in biomass, may have been a significant source of nutrients, though fine root biomass is strongly linked to nutrient uptake (Kulmatiski et al. 2017). Additionally, our study did not account for soil deeper than $30 \mathrm{~cm}$, nor the importance of horizontal root partitioning. There is evidence that, in some ecosystems, these root dynamics can explain the positive relationship between species richness and biomass (von Felten and Schmid 2008). Nevertheless, one would expect to find evidence for a vertical niche partitioning even in these conditions, where a strong nutrient gradient exists across the upper $30 \mathrm{~cm}$ of soil (Figure S3).

The effect of the presence/absence of $C$. glauca on the positive diversity-function relationship is consistent with the "selection effect." The selection hypothesis postulates that high production in species rich communities could be due to the higher chance of there being a more productive species (Aarssen 1997). However, since naturally assembled forests are extremely complex and lack monocultures, we cannot fully explore the selection effect and can only conclude that the selection effect may exist in these 
subtropical forests. Further studies in controlled conditions could elucidate the

contribution of a single species on root biomass productivity in mixed species forests.

\section{Stand density-dependent effects on fine root biomass}

SEM was used to understand the drivers of the relationship between species richness and fine root biomass, whereby stand density, forest types and soil nutrients were taken into account. Tree species richness and fine root biomass were significantly correlated, indicating that diversity and biomass can feedback on each other (Grace et al. 2016). Furthermore, tree species richness and stand density were significantly correlated, with stand density affecting fine root biomass, while the effects of forest types and soil nutrients were very weak (Figure 6). These results show that stand density has stronger effects on fine root biomass than species richness in naturally assembled forests. This result is in contrast with a controlled glasshouse experiment, in which root biomass increased with species richness but remained constant with a similar increase gradient of plant density (He et al. 2005). This suggests that the relationship between species richness and biomass may be weaker in naturally assembled forests (van der Plas 2019).

In natural forests, it is difficult to disentangle the relationship between aboveground species richness and stand density, which could result from more species-rich communities supporting higher stand density or higher density could be the consequence of higher species richness. Our results suggest it depends on the interaction between stand density and aboveground species richness, with lower standing fine root biomass at low density and low species richness, an effect which disappears at high density (Figure 7c).

We contend that there are at least two alternative explanations for the interaction between stand density and aboveground species richness. One explanation stems from the interpretation of the higher density in more diverse mixtures (Figure 1a and Figure 7) as both the cause and consequence of regeneration-niche driven recruitment processes. 
From this perspective, the results are in alignment with the negative biotic feedback hypothesis which produces a positive relationship between species richness and biomass (Barry et al. 2019) because species differ in their enemies (pests, pathogens and herbivores) and the interactions between plant and enemy may create a strong conspecific negative density dependence. This negative density dependence effect (also known as Janzen-Connell effect) leads to reduced plant performance in low diversity stands and is particularly well documented in forests (Packer and Clay 2000, Lambers et al. 2002, Freckleton and Lewis 2006). The second explanation of why the positive diversity-root biomass relationship was highest at low stand density and disappeared at high stand density is the saturation of the effect under conditions of high stand density. This could be linked to the existence of an upper limit in the competitive advantage provided to a tree by further increasing its investment in fine root biomass in conditions of high competition for soil resources.

This study found an increase in fine root biomass with tree species richness along a diversity gradient across three different secondary forests. Testing for the belowground mechanisms driving this relationship revealed a lack of support for the spatial root partitioning hypothesis that greater fine roots grow in subsoil layers. Instead, we found that the evenness of the root biomass within soil horizons was strongly affected by the interaction between aboveground species richness and soil nutrient content in the topsoil $(0-10 \mathrm{~cm})$. This implies there is no inherent advantage for a particular species in colonizing nutrient hotspots, indicating symmetric root growth strategies are common in nutrient rich forest soils. SEM revealed that stand density was the dominant factor explaining the variation in effect of aboveground species richness on fine root biomass rather than soil nutrients. Fine root biomass also depended on the interaction between tree species richness and stand density, suggesting that density-dependent biotic feedbacks affecting tree recruitment should be considered as a driver of belowground productivity 
in diverse subtropical forests. Finally, we conclude that patterns of root distribution associated with resource partitioning are unlikely in contexts where soil nutrients are heterogeneously distributed.

\section{Acknowledgements}

We would like to thank the China Scholarship Council for the support to our joint Ph.D. program grant (201808430207) and the opportunity to work at the Centre for Functional and Evolutionary Ecology of Montpellier, France.

\section{Funding}

This study was funded by the National Natural Science Foundation of China (31570447 and 31870431) and the Huitong Forest Ecological Station funded by the State Forestry Administration of China (2019132159).

Data Accessibility: The fine root biomass data will be deposited in Dryad Digital Repository, when the manuscript is accepted.

Statement of authorship: WX designed the study; Data collection and analyses were performed by WZ, BZ, SO, LC and WX; Statistical analyses were performed by WZ and AM with input from BZ, SO, LC, WX; The manuscript was written by WZ, AM and WX, with input from BZ, YZ, GTF and OJV.

Conflict of interest statement: The authors declare that they have no conflict of interest.

\section{References}


Aarssen, L. W. 1997. High productivity in grassland ecosystems: effected by species diversity or productive species. - Oikos 80: 183-184.

Adams, T. S. et al. 2013. Foraging strategies in trees of different root morphology: The role of root lifespan. - Tree Physiol. 33: 940-948.

Bardgett, R. D. and van Der Putten, W. H. 2014. Belowground biodiversity and ecosystem functioning. - Nature 515: 505.

Bardgett, R. D. et al. 2014. Going underground: Root traits as drivers of ecosystem processes. - Trends Ecol. Evol. 29: 692-699.

Barr, A. G. et al. 2004. Inter-annual variability in the leaf area index of a boreal aspen-hazelnut forest in relation to net ecosystem production. - Agr. Forest Meteorol. 126: 237-255.

Barry, K. E. et al. 2019. The Future of Complementarity: Disentangling Causes from Consequences. - Trends Ecol. Evol. 34: 167-180.

Barry, K. E. et al. 2020. Limited evidence for spatial resource partitioning across temperate grassland biodiversity experiments. - Ecology 10: e02905.

Brassard, B. W. et al. 2013. Tree species diversity increases fine root productivity through increased soil volume filling. - J. Ecol. 101: 210-219.

Bruelheide, H. et al. 2011. Community assembly during secondary forest succession in a Chinese subtropical forest. - Ecology 81: 25-41.

Caldwell, M. M. et al. 1996. Species interactions at the level of fine roots in the field:influence of soil nutrient heterogeneity and plant size. - Oecologia 106: $440-447$.

Cardinale, B. J. et al. 2007. Impacts of plant diversity on biomass production increase through time because of species complementarity. - Proc. Natl Acad. Sci. USA 104: $18123-18128$. 
Cardinale, B. J. et al. 2011. The functional role of producer diversity in ecosystems. Am. J. Bot. 98: 572-592.

Chisholm, R. A. et al. 2013. Scale-dependent relationships between tree species richness and ecosystem function in forests. - J. Ecol. 101: 1214-1224.

Connell, J. H. 1971. On the role of natural enemies in preventing competitive exclusion in some marine animals and in rain forest trees. In: Den Boer PJ, Gadwell PR (eds) Dynamics of populations. Wageningen, Netherlands.

Craine, J. M. 2006. Competition for nutrients and optimal root allocation. - Plant Soil: $171-185$.

Cristiano, P. M. et al. 2014. High NDVI and potential canopy photosynthesis of south American subtropical forests despite seasonal changes in leaf area index and air temperature. - Forests 5: 287-308.

de Kroon, H. et al. 2012. Root responses to nutrients and soil biota : drivers of species coexistence and ecosystem productivity. - J. Ecol. 100: 6-15.

Domisch, T. et al. 2015. Does species richness affect fine root biomass and production in young forest plantations? - Oecologia 177: 581-594.

Eissenstat, D. M. 1992. Costs and benefits of constructing roots of small diameter. - J. Plant Nutri. 15: 763-782.

Forrester, D. I. and Bauhus, J. 2016. A review of processes behind diversity—productivity relationships in forests. - Curr. For. Rep. 2: 45-61.

Frank, D. A. et al. 2015. Fine-scale belowground species associations in temperate grassland. - Mol. Ecol. 24: 3206-3216.

Freckleton, R. P. and Lewis, O. T. 2006. Pathogens, density dependence and the coexistence of tropical trees. - Proc. R. Soc. B 273: 2909-2916.

Freschet, G. T. and Roumet, C. 2017. Sampling roots to capture plant and soil functions. Funct. Ecol. 31: 1506-1518. 
Gale, M. R. and Grigal, D. F. 1987. Vertical root distribution of nothern tree species in relation to successional status. - Can. J. For. Res. 17: 829-834.

Gersani, M. et al. 2001. Tragedy of the commons as a result of root competition. - J. Ecol. 89: 660-669.

Gould, I. J. et al. 2016. Plant diversity and root traits benefit physical properties key to soil function in grasslands. - Ecol. Lett. 19: 1140-1149.

Gower, S. T. et al. 1996. A global trend in belowground carbon allocation: can we use the relationship at smaller scales? - Ecology 77: 1750-1755.

Grada, A. and Weinbrecht, K. 2013. Next-generation sequencing: methodology and application. - J. Invest. Dermatol. 133:e11.

Grace, J. B. et al. 2016 Integrative modelling reveals mechanisms linking productivity and plant species richness. - Nature 529:390-393.

He, J. et al. 2005. Density may alter diversity-productivity relationships in experimental plant communities. - Basic Appl. Ecol. 6: 505-517.

Hendrick, R. L. and Pregitzer, K. S. 1992. The demography of fine roots in a northern hardwood forest. - Ecology 73: 1094-1104.

Hendriks, M. et al. 2015. Spatial heterogeneity of plant-soil feedback affects root interactions and interspecific competition. - New Phytol. 207: 830-840.

Hiiesalu, I. et al. 2012. Plant species richness belowground: Higher richness and new patterns revealed by next-generation sequencing. - Mol. Ecol. 21: 2004-2016.

Hodge, A. 2004. The plastic plant: root responses to heterogeneous supplies of nutrients. - New Phytol. 162: 9-24.

Hooper, D. U. et al. 2005. Effects of biodiversity on ecosystem functioning: A consensus of current knowledge. - Ecol. Monogr. 75: 3-35.

Huang, G. et al. 2010. Linking root morphology, longevity and function to root branch order: A case study in three shrubs. - Plant Soil 336: 197-208. 
Iio, A. et al. 2014. Global dependence of field-observed leaf area index in woody species on climate: A systematic review. - Global Ecol. Biogeogr. 23: 274-285.

Institute of Soil Science, CAS. 1978. Analytical methods of soil physics and chemistry. Shanghai Scientific and Technical Publishers, Shanghai, China.

Jackson, R. B. et al. 1997. A global budget for fine root biomass, surface area, and nutrient contents. -Proc. Natl Acad. Sci. USA 94: 7362-7366.

Jacob, A. et al. 2013. On the significance of belowground overyielding in temperate mixed forests: Separating species identity and species diversity effects. - Oikos 122: $463-473$.

Janzen, D. H. 1970. Herbivores and the number of tree species in tropical forests. - Am. Nat. 104: 501-528.

Jiang, F. et al. 2017. Spatial variations in soil organic carbon, nitrogen and phosphorus concentrations related to stand characteristics in subtropical areas. - Plant Soil 413: 289-301.

Johnson, D. J. et al. 2012. Conspecific negative density dependence and forest diversity. Science 338: 904-908.

Jones, F. A. et al. 2011. The roots of diversity: Below ground species richness and rooting distributions in a tropical forest revealed by DNA barcodes and inverse modeling. PLoS ONE 6: e24506.

Kennedy, T. A. et al. 2002. Biodiversity as a barrier to ecological invasion. - Nature 417: 636-638.

Kesanakurti, P. R. et al. 2011. Spatial patterns of plant diversity below-ground as revealed by DNA barcoding. - Mol. Ecol. 20: 1289-1302.

Kress, W. J. et al. 2009. Plant DNA barcodes and a community phylogeny of a tropical forest dynamics plot in Panama. -Proc. Natl Acad. Sci. USA 106: 18621-18626. 
Kulmatiski, A. et al. 2017. Water and nitrogen uptake are better associated with resource availability than root biomass. - Ecosphere 8: e01738. 10.1002/ecs2.1738.

Lambers, J. H. R. et al. 2002. Density-dependent mortality and the latitudinal gradient in species diversity. - Nature 417: 732-735.

Le Dantec, V. et al. 2000. Interannual and spatial variation in maximum leaf area index of temperate deciduous stands. - For. Ecol. Manage. 134: 71-81.

Leuschner, C. et al. 2009. Functional role of forest diversity: Pros and cons of synthetic stands and across-site comparisons in established forests. - Basic Appl. Ecol. 10: $1-9$.

Liang, J. et al. 2016. Positive biodiversity-productivity relationship predominant in global forests. - Science 354: aaf8957.

Liu, C. et al. 2014. Standing fine root mass and production in four Chinese subtropical forests along a succession and species diversity gradient. - Plant Soil 376: 445-459.

Long, J. 2018. jtools: Analysis and Presentation of Social Scientific Data. R Package Version 0.7. 0. Available online: https://cran. r-project. org/package=jtools (accessed on 21 February 2018). trükis.

Ma, Z. and Chen, H. Y. H. 2016. Effects of species diversity on fine root productivity in diverse ecosystems: a global meta-analysis. - Global Ecol. Biogeogr. 25: 1387-1396.

Ma, Z. and Chen, H. Y. H. 2017. Effects of species diversity on fine root productivity increase with stand development and associated mechanisms in a boreal forest. $-\mathrm{J}$. Ecol. 105: 237-245.

Ma, Z. and Chen, H. Y. H. 2018. Positive species mixture effects on fine root turnover and mortality in natural boreal forests. - Soil Biol. Biochem. 121: 130-137. 
Mahaut, L. et al. 2020. Multiple facets of diversity effects on plant productivity: species richness, functional diversity, species identity and intraspecific competition. Funct. Ecol. 34: 287-298.

Marquard, E. et al. 2009. Positive biodiversity-productivity relationship due to increased plant density. - J. Ecol. 97: 696-704.

Meinen, C. et al. 2009. Root growth and recovery in temperate broad-leaved forest stands differing in tree species diversity. - Ecosystems 12: 1103-1116.

Milcu, A. et al. 2016. Plant functional diversity increases grassland productivity-related water vapor fluxes: an Ecotron and modeling approach. - Ecology 97: 2044.

Mommer, L. et al. 2010. Unveiling below-ground species abundance in a biodiversity experiment: a test of vertical niche differentiation among grassland species. $-\mathrm{J}$. Ecol. 98: 1117-1127.

Mommer, L. et al. 2011. Belowground DNA-based techniques: untangling the network of plant root interactions. - Plant Soil 348: 115-121.

Mommer, L. et al. 2015. Diversity effects on root length production and loss in an experimental grassland community. - Funct. Ecol. 29: 1560-1568.

Mommer, L. et al. 2016. Root-Root Interactions: Towards A Rhizosphere Framework. Trends Plant Sci. 21: 209-217.

Mommer, L. et al. 2018. Lost in diversity: the interactions between soil-borne fungi, biodiversity and plant productivity. - New Phytol. 218: 542-553.

Mueller, K. E. et al. 2013. Root depth distribution and the diversity-productivity relationship in a long-term grassland experiment. - Ecology 94: 787-793.

Nakagawa, S. and Schielzeth, H. 2013. A general and simple method for obtaining R2 from generalized linear mixed-effects models. - Methods Ecol. Evol. 2: 133-142.

Oram, N. J. et al. 2018. Below-ground complementarity effects in a grassland biodiversity experiment are related to deep-rooting species. - J. Ecol. 106: 265-277. 
Ouyang, S. et al. 2016. Significant effects of biodiversity on forest biomass during the succession of subtropical forest in south China. - For. Ecol. Manage. 372: 291-302

Packer, A. and Clay, K. 2000. Soil pathogens and spatial patterns of seedling mortality in a temperate tree. - Nature 404: 278.

Pasek, J. et al. 2020. Package 'weights'.

Pärtel, M. et al. 2012. Below-ground plant species richness: New insights from DNA-based methods. - Funct. Ecol. 26: 775-782.

Petermann, J. S. et al. 2008. Janzen-Connell effects are widespread and strong enough to maintain diversity in grasslands. - Ecology 89: 2399-2406.

Pielou, E. C. 1966. The measurement of diversity in different types of biological collections. - J. Theor. Biol. 13: 131-144.

Pinheiro, J. et al. 2017. Nlme: Linear and Nonlinear Mixed Effects Models. R package version 3.1-128.

R Development Core Team 2015. R:a language and environment for statistical computing. R Foundation for Statistical Computing, Vienna http://www.R-project.org/.

Rosseel, Y. 2012. Lavaan: An R package for structural equation modeling and more. Version 0.5-12 (BETA). - J. stat. softw. 48: 1-36.

Schnitzer, S. A. et al. 2011. Soil microbes drive the classic plant diversity-productivity pattern. - Ecology 92: 296-303.

Tilman, D. 1999. The Ecological Consequences of Changes in Biodiversity: A Search for General Principles. - Ecology 80: 1455-1474.

Valverde-Barrantes, O. J. et al. 2015. Aggregated and complementary: Symmetric proliferation, overyielding, and mass effects explain fine-root biomass in soil patches in a diverse temperate deciduous forest landscape. - New Phytol. 205: $731-742$. 
van der Plas, F. 2019. Biodiversity and ecosystem functioning in naturally assembled communities. - Biol. Rev. 94: 1220-1245.

von Felten, S. and Schmid, B. 2008. Complementarity among species in horizontal versus vertical rooting space. - J. Plant Ecol. 1: 33-41.

Williams, L. J. et al. 2017. Spatial complementarity in tree crowns explains overyielding in species mixtures. - Nature Ecol. Evol. 1: 63.

WRB: World Reference Base for Soil Resources, Ed. FAO, IUSS, ISRIC, Rapport FAO 103, Rome, 132 pp., 2006.

$\mathrm{Wu}, \mathrm{H}$. et al. 2019. Linkage between tree species richness and soil microbial diversity improves phosphorus bioavailability. - Funct. Ecol. 33:1549-1560.

Xiang, W. et al. 2015. Fine root interactions in subtropical mixed forests in China depend on tree species composition. - Plant Soil 395: 335-349.

Yu, G. et al. 2014. High carbon dioxide uptake by subtropical forest ecosystems in the East Asian monsoon region. -Proc. Natl Acad. Sci. USA 111: 4910-4915.

Zeng, W. et al. 2015. A molecular method to identify species of fine roots and to predict the proportion of a species in mixed samples in subtropical forests. - Front. Plant Sci. 6: 1-10.

Zeng, W. et al. 2017. Measurement of belowground diversity of fine roots in subtropical forests based on a quantitative real-time PCR (qPCR) method. - Plant Soil 420: $539-552$.

Zhang, Y. et al. 2012. Forest productivity increases with evenness, species richness and trait variation: A global meta-analysis. - J. Ecol. 100: 742-749.

Zhu, W. et al. 2016. Spatial and seasonal variations of leaf area index (LAI) in subtropical secondary forests related to floristic composition and stand characters. Biogeosciences 13: 1-41. 
Zuur, A. et al. 2009. Mixed effects models and extensions in ecology with R. - Springer Science + Business Media, LLC, New York. 


\section{Figure legends}

Figure 1 A schematic framework depicting the potential mechanisms underlying the effect of tree species richness on fine root biomass. Panel (a) depicts the hypothesis that fine root biomass increases with aboveground tree species richness. Panel (b) illustrates the trends in the inverse of the coefficient of variation (inverse CV) of fine root biomass (FRB) across soil profile increases expected from the hypothesis that spatial root partitioning is responsible for the increase in fine root biomass with aboveground tree species richness. Panel (c) and (d) depict whether symmetric root growth (c) or asymmetric root growth $(\mathrm{d})$ leads to higher fine root biomass in nutrient-rich areas as tree species increases. Symmetric root growth occurs when all species have an equal growth capacity and their root evenly spread in nutrient-rich sites, so that the inverse CV of FRB remains stable with aboveground tree species richness (c). Otherwise, asymmetric root growth occurs when fine roots of particular species dominate nutrient-rich areas and their root less evenly spread, so that the inverse $\mathrm{CV}$ of FRB decreases with aboveground tree species richness $(d)$.

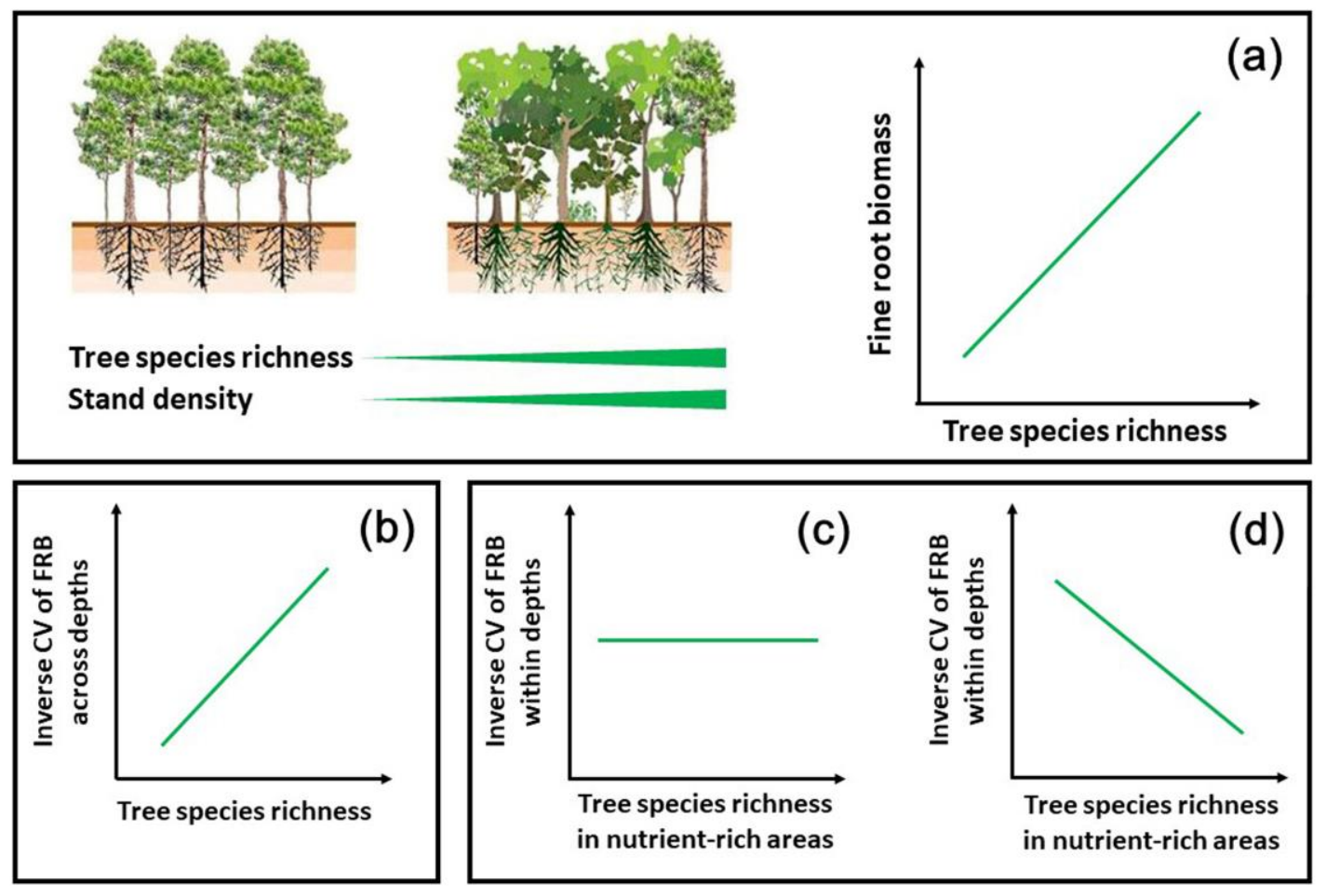


Figure 2 The relationship between belowground species richness estimated with the

DNA-sequencing and aboveground species richness in all forests $(\mathrm{n}=91)$ in $(\mathrm{a})$, the early successional species-dominated mixed forest stand $(\mathrm{PM})(\mathrm{n}=30)(\mathrm{b})$, the broad-leaved deciduous species-dominated mixed forest stand $(\mathrm{CA})(\mathrm{n}=31)(\mathrm{c})$, and the late successional broad-leaved evergreen species-dominated forest stand $(\mathrm{CG})(\mathrm{n}=30)(\mathrm{d})$. The red line depicts the linear regression and the variance explained by the entire model, including both fixed and random effects, is inset on each panel.

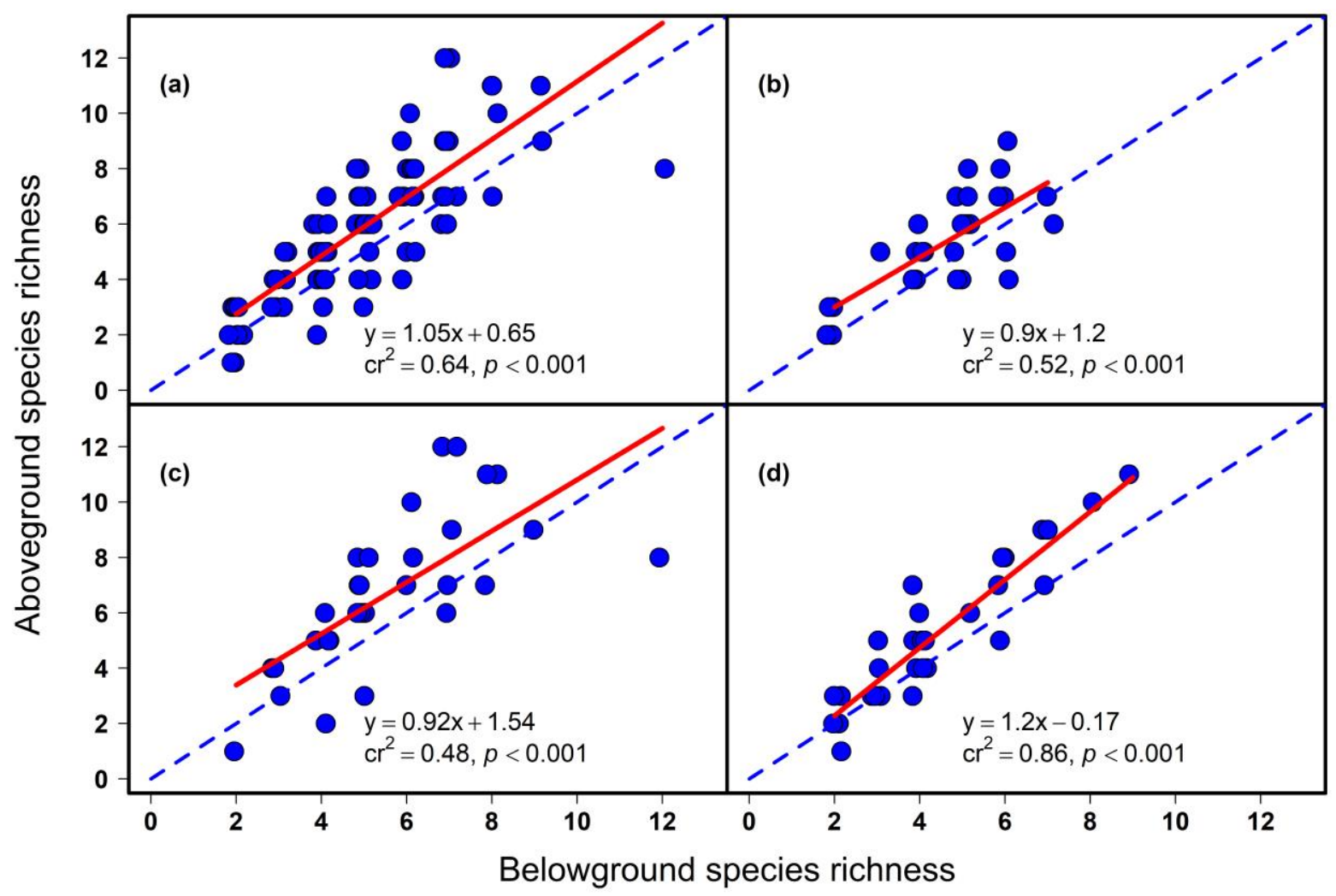

'This article is protected by copyright. All rights reserved.' 
Figure 3 In panel (a), the relationships between aboveground species richness and fine root biomass in all samples from all forests $(\mathrm{n}=91)$. In panel $(\mathrm{b})$, the relationships between aboveground species richness and leaf area index (LAI) in all samples from all forests $(\mathrm{n}=91)$. In panel $(\mathrm{c})$, the relationships between fine root biomass and LAI in all samples from all forests $(\mathrm{n}=91)$. In panel $(\mathrm{d})$, the relationships between aboveground species richness and fine root biomass for 0-10 cm (brown), 10-20 cm (orange) and 20-30 cm depth (yellow) in all samples from all forests $(n=273)$. Lines depict linear regressions and the shaded areas indicate $95 \%$ confidence intervals. Variance explained by the entire model, including both fixed and random effects represents, is inset on each panel.
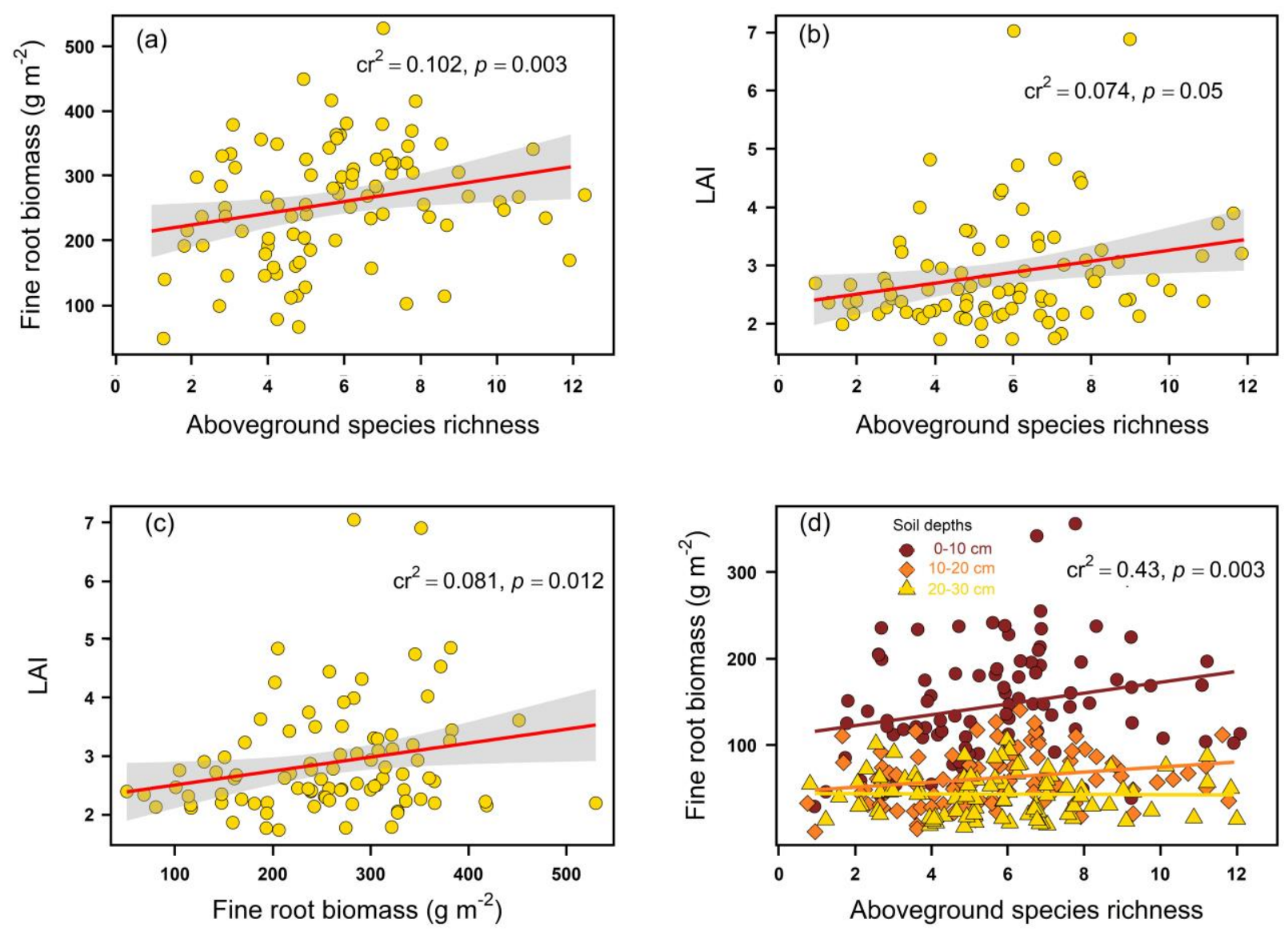

'This article is protected by copyright. All rights reserved.' 
Figure 4 In panel (a), the impact of aboveground species richness on the inverse CV of fine root biomass (FRB) across all soil layers $(\mathrm{n}=91)$. Variance explained by the entire model, including both fixed and random effects, represents the conditional $\mathrm{r}^{2}\left(\mathrm{cr}^{2}\right)$. In panel (b), the impact of the interaction between aboveground species richness and depth interaction on the inverse CV of FRB within depths for the soil depth layers of 0-10 cm (brown), 10-20 cm (orange), and 20-30 cm (yellow) $(\mathrm{n}=273)$. Lines depict the fitted linear regression lines and the shaded areas indicate the 95\% confidence intervals. Variance explained by the entire model, including both fixed and random effects, represents the conditional $\mathrm{r}^{2}\left(\mathrm{cr}^{2}\right)$.

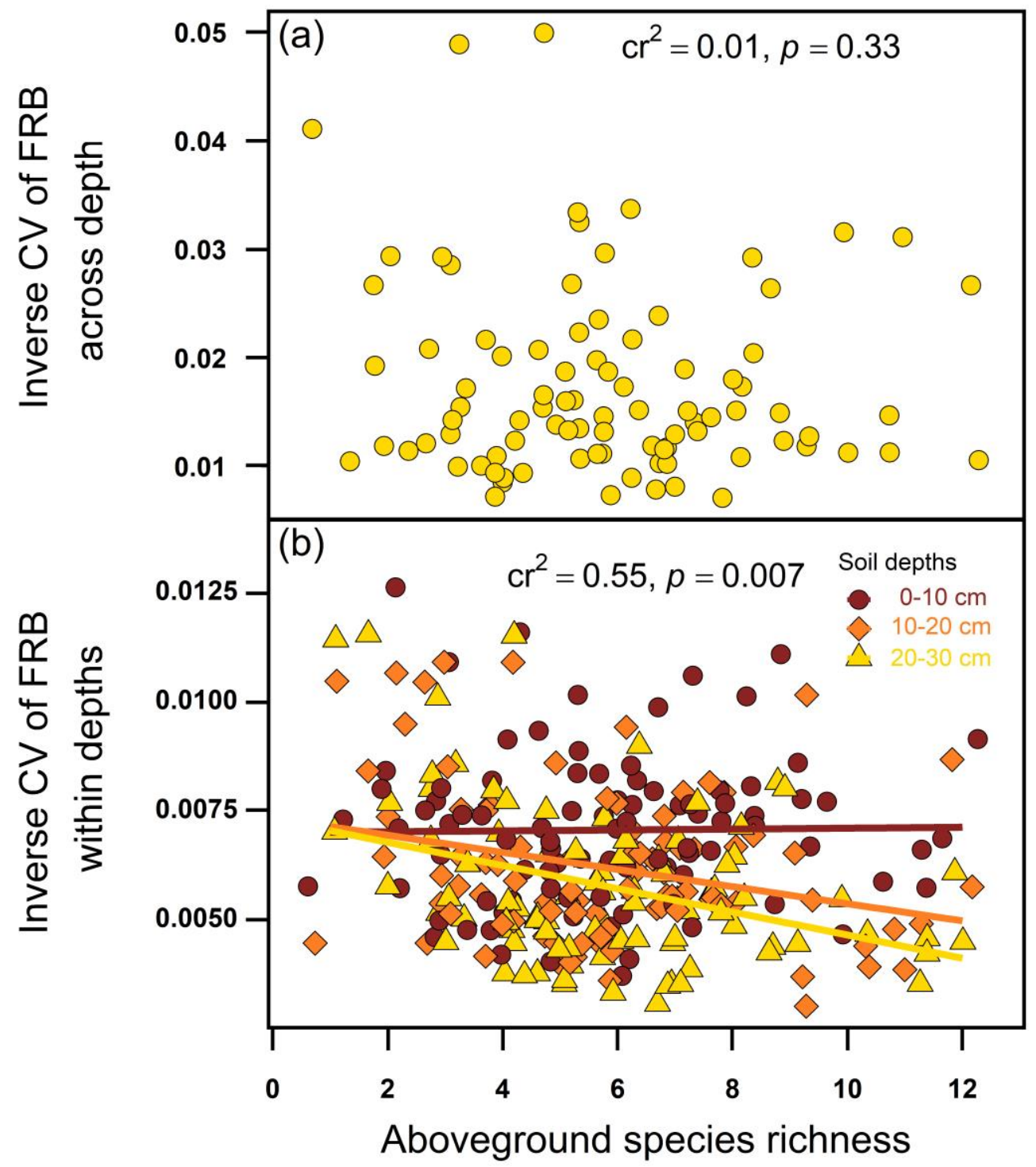

'This article is protected by copyright. All rights reserved.' 
Figure 5 Interaction plot depicting the impact of (a) aboveground species richness $\times$ soil organic carbon $(\mathrm{C}),(\mathrm{b})$ aboveground species richness $\times$ soil nitrogen $(\mathrm{N})$ and $(\mathrm{c})$ aboveground species richness $\times$ soil phosphorus $(\mathrm{P})$ on the inverse $\mathrm{CV}$ of fine root biomass (FRB) within soil depth of $0-10 \mathrm{~cm}$ ( $\mathrm{n}=91$ for each soil nutrients). The filled circles represent high soil nutrient content and open triangles represent low soil nutrient content. The change tendency of inverse CV of FRB within soil depth of $0-10 \mathrm{~cm}$ with aboveground tree species richness in high soil nutrient content is shown by solid blue lines, where those in low soil nutrient content are shown by dashed blue lines. Variance explained by the entire model, including both fixed and random effects represents the conditional $\mathrm{r}^{2}\left(\mathrm{cr}^{2}\right)$. High soil nutrient concentrations are defined as those higher than the average value of all + standard deviation, whereas the low values are those lower than this average value - standard deviation.

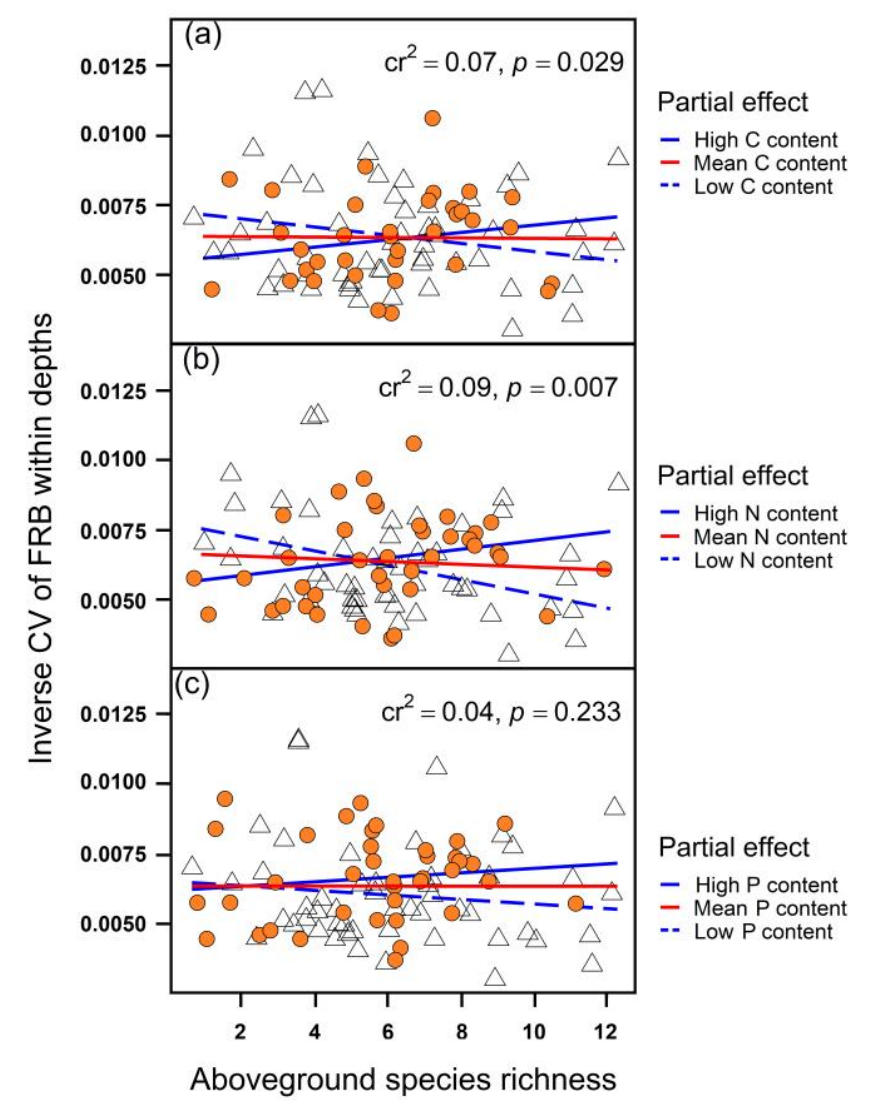

'This article is protected by copyright. All rights reserved.' 
Figure 6 The results of structural equation model showing the effects of aboveground tree species richness, stand density, forest types and soil nutrients on fine root biomass (n =91). The coefficients are standardized prediction coefficients for each causal path. Solid blue lines represent significant and positive effects and dashed blue lines indicate insignificant and positive effects. Dashed grey lines represent insignificant and negative effects. Numbers above solid arrows are standardized path coefficients ${ }^{*} p<0.05,{ }^{*} p<$ $0.01, * * * p<0.001)$ and width of an arrow indicates the strength of the relationships. $R^{2}$ denotes the proportion of variance explained. CFI corresponds to the comparative fit index. RMSEA corresponds to the root mean square error of approximation. SRMR corresponds to the standardized root mean square residual. Stand density was standardized by weighting the basal area in each plot.

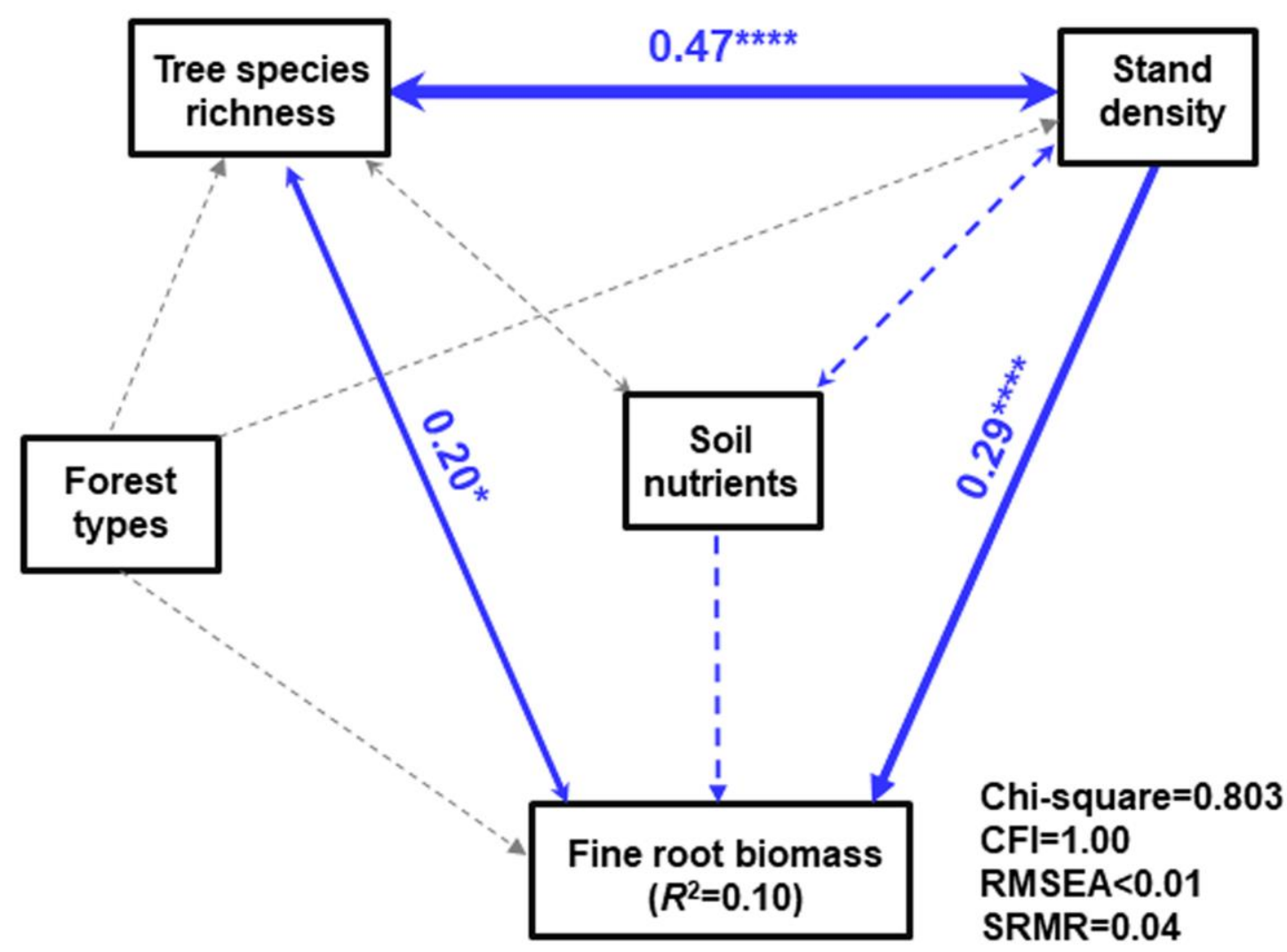

'This article is protected by copyright. All rights reserved.' 
Figure 7 In panel (a), the impact of aboveground species richness on stand density $(\mathrm{n}=$ 91). In panel (b), the impact of stand density on fine root biomass $(n=91)$. Lines depict the fitted linear regression lines and the shaded areas indicate the $95 \%$ confidence intervals. (c) Interaction plot depicting aboveground species richness $\times$ stand density interaction $(n=91)$; The filled circles represented high stand density and open circles represented low stand density; The change tendency of fine root biomass with aboveground tree species richness in high stand density is shown by solid blue line, whereas that in low stand density is shown by dashed blue line. Variance explained by the entire model, including both fixed and random effects represents the conditional $\mathrm{r}^{2}\left(\mathrm{cr}^{2}\right)$. Stand density was standardized by weighting the basal area in each plot. High stand density is defined as being greater than the average value + standard deviation whereas the low density is lower than the average value - standard deviation.
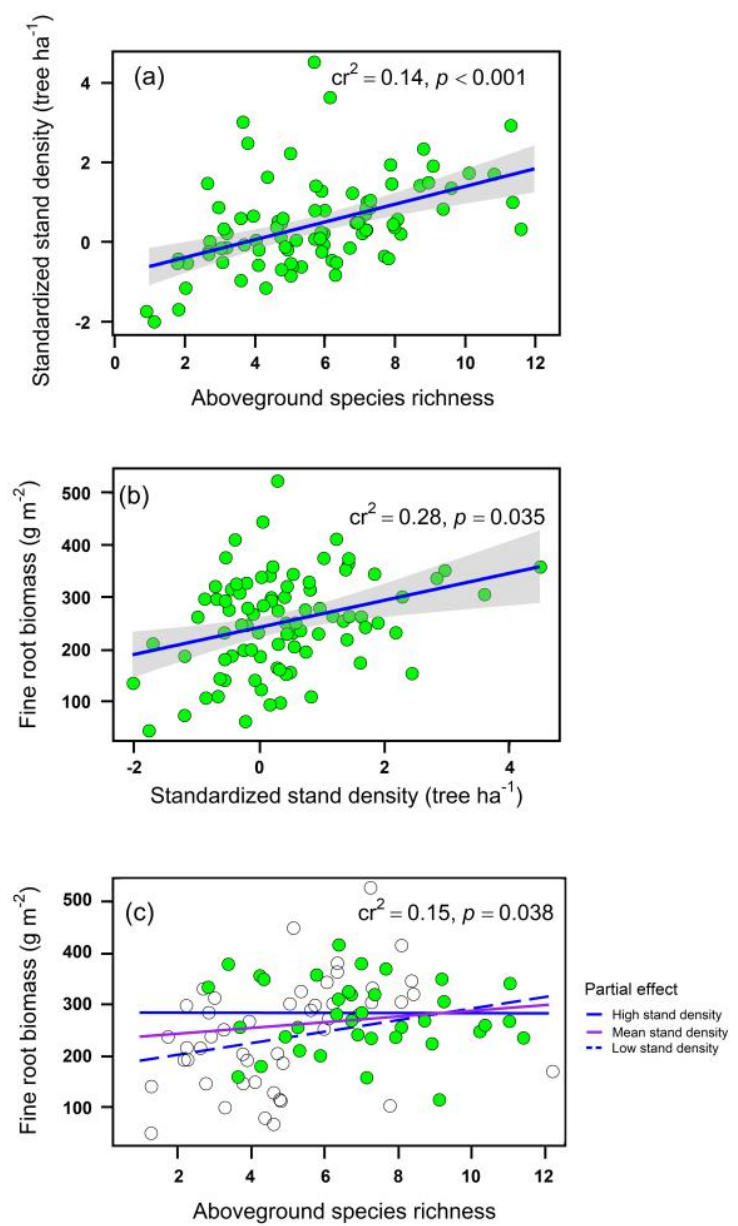

'This article is protected by copyright. All rights reserved.' 


\section{Table Legends}

Table 1 Effects of aboveground tree species richness, soil depth (Depth) and their interaction, on fine root biomass $\left(\mathrm{g} \mathrm{m}^{-2}\right)(\mathrm{n}=273)$ and the inverse of coefficient of variation $(1 / \mathrm{CV})$ of fine root biomass across $(n=91)$ and within soil depths $(n=273)$. NA represents variables that were not retained in the minimal adequate models following AIC-based model comparisons. Variance explained by the fixed effects represents the marginal $\mathrm{r}^{2}\left(\mathrm{mr}^{2}\right)$ whereas the variance explained by the entire model, including both fixed and random effects represents the conditional $\mathrm{r}^{2}\left(\mathrm{cr}^{2}\right)$.

\begin{tabular}{llll}
\hline Source & Fine root biomass & 1/CV across depths & 1/CV within depths \\
\hline $\begin{array}{l}\text { Species } \\
\text { richness }\end{array}$ & $\mathrm{F}_{1,87}=10.35, p=0.002$ & $\mathrm{~F}_{1,86}=0.96, p=0.431$ & $\mathrm{~F}_{1,87}=6.97, p=0.009$ \\
$\begin{array}{l}\text { Depth } \\
\begin{array}{l}\text { Species } \\
\text { richness } \times\end{array}\end{array}$ & $\mathrm{F}_{2,178}=18.93, p<0.001$ & $\mathrm{NA}$ & $\mathrm{F}_{2,178}=23.27, p<0.001$ \\
$\begin{array}{l}\text { Depth } \\
\mathrm{mr}^{2}=0.1414, \mathrm{cr}^{2}=0.4432\end{array}$ & $\mathrm{mr}^{2}=0.0405, \mathrm{cr}^{2}=0.0405$ & $\mathrm{mr}^{2}=0.1323, \mathrm{cr}^{2}=0.5523$ \\
\hline
\end{tabular}


Table 2 Effects of aboveground tree species richness and total soil organic carbon (C), nitrogen $(\mathrm{N})$ and phosphorus $(\mathrm{P})$ contents and their interactions on the inverse of the coefficient of variation $(1 / \mathrm{CV})$ of fine root biomass within soil depths of $0-10 \mathrm{~cm}(\mathrm{n}=$ 91). Variance explained by the fixed effects represents the marginal $r^{2}\left(m r^{2}\right)$ whereas the variance explained by the entire model, including both fixed and random effects, represents the conditional $\mathrm{r}^{2}\left(\mathrm{cr}^{2}\right)$.

\begin{tabular}{llllll}
\hline Source & $\begin{array}{l}1 / \mathrm{CV} \text { within } \\
\text { depths }\end{array}$ & Source & $1 / \mathrm{CV}$ within depths & Source & $\begin{array}{l}1 / \mathrm{CV} \text { within } \\
\text { depths }\end{array}$ \\
\hline $\begin{array}{l}\text { Species } \\
\text { richness }\end{array}$ & $\mathrm{F}_{1,87}=0.17, p=0.6764 \begin{array}{l}\text { Species } \\
\text { richness }\end{array}$ & $\mathrm{F}_{1,87}=0.16 p=0.6917$ & $\begin{array}{l}\text { Species } \\
\text { richness }\end{array}$ & $\mathrm{F}_{1,87}=0.13, p=0.7155$ \\
$\mathrm{C}$ & $\mathrm{F}_{1,87}=0.56, p=0.4566 \mathrm{~N}$ & $\mathrm{~F}_{1,87}=0.18, p=0.6675$ & $\mathrm{P}$ & $\mathrm{F}_{1,87}=2.19, p=0.1426$ \\
$\begin{array}{l}\mathrm{C} \\
\times \text { Species } \\
\text { richness }\end{array}$ & $\mathrm{F}_{1,87}=4.90, p=0.0294 \begin{array}{l}\mathrm{N} \\
\text { richness }\end{array}$ & $\mathrm{F}_{1,87}=7.72, p=0.0067$ & $\begin{array}{l}\mathrm{P} \\
\times \text { Species } \\
\text { richness }\end{array}$ & $\mathrm{F}_{1,87}=1.44, p=0.2329$ \\
& $\begin{array}{l}\mathrm{mr}^{2}=0.0689, \\
\mathrm{cr}^{2}=0.0689\end{array}$ & $\mathrm{mr}^{2}=0.0949, \mathrm{cr}^{2}=0.0949$ & $\begin{array}{l}\mathrm{mr}^{2}=0.0455, \\
\mathrm{cr}^{2}=0.0455\end{array}$ \\
\hline
\end{tabular}

